\title{
Distribution and genensis of mercury in giant gas fields in China
}

\author{
LI JIAN ${ }^{12}$, HAN ZHONGXI ${ }^{12}$, YANQITUAN ${ }^{12}$, HAO \\ AISHENG $^{12}$
}

${ }^{1}$ Research Institute of Petroleum Exploration \& Development, PetroChina, Beijing 100083, China

${ }^{2}$ Key

Laboratory of Gas Reservoir Formation and Development,

CNPC, Langfang 065007, China

Mercury is a toxic and corrosive element and its presence brings potential safety hazards to gas field production. Clarifying the distribution and genesis of mercury in giant gas fields in China is of great significance for the safe production of natural gas fields, extending the life of natural gas pipelines and environment protection. For this reason, the mercury content in natural gas samples from more than 500 gas wells in eight large gas bearing basins of China was tested, mercury release experiments on two coal samples from different areas were conducted, and the mercury content of 11 coal samples from different gas wells of Ordos Basin was tested.

Studies show that the distribution of mercury in coal-type gas in China has following three characteristics. (1) Mercury content of coal derived gas is generally much higher than that of oil derived gas. All the high mercury content gas samples $\left(>30 \mu \mathrm{g} / \mathrm{m}^{3}\right)$ are coal derived gas. Mercury content is low $\left(<10 \mu \mathrm{g} / \mathrm{m}^{3}\right)$ for oil derived gas samples.(2) The mercury content of coal derived gas in different gas fields vary form $0.01 \mu \mathrm{g} / \mathrm{m}^{3}$ to $2240 \mu \mathrm{g} / \mathrm{m}^{3}$. There are large differences in mercury content between different basins and even between different gas fields in the same basin. (3)Generally, mercury content in coal derived gas increases with the increase of production layer depth.

Mercury in coal derived natural gas mainly originated from the source rock. The pyrolysis experiment of two coal samples show that coal can produce natural gas with high mercury content during the process of thermal evolution. The mercury content of coal derived natural gas is controlled mainly by the temperature of source rock and the sulfur environment of reservoir. According to lithospheric material cycling process and oil-gas formation process, the formation of mercury in coal derived gas can be divided into four stages, transportation and deposition, shallow burial, deep burial, and preservation and destruction. 